\title{
Stratification of Health Professional Education and Its Funding Disparities: Evidence From China During the Period of 1998-2017
}

\author{
Wenjuan Gao ${ }^{1 \dagger}$, Wenzhuo $\mathrm{Li}^{2+}$, Yue Zang ${ }^{3,4}$, Yuxin Zhong ${ }^{3,4}$ and Hongbin Wu ${ }^{3,5 *}$ \\ ${ }^{1}$ Institute of Higher Education, Beihang University, Beijing, China, ${ }^{2}$ Education Section, Aerospace Center Hospital/Peking \\ University Aerospace School of Clinical Medicine, Beijing, China, ${ }^{3}$ Institute of Medical Education, Peking University, Beijing, \\ China, ${ }^{4}$ Graduate School of Education, Peking University, Beijing, China, ${ }^{5}$ National Center for Health Professions Education \\ Development, Peking University, Beijing, China
}

\section{OPEN ACCESS}

Edited by:

Mohammed S. Razzaque,

Lake Erie College of Osteopathic

Medicine, United States

Reviewed by:

Jay Pan,

Sichuan University, China

Abdur Rafi,

Rajshahi Medical College, Bangladesh

*Correspondence:

Hongbin Wu

wuhongbin@pku.edu.cn

${ }^{\dagger}$ These authors have contributed equally to this work

Specialty section:

This article was submitted to

Public Health Education and

Promotion,

a section of the journal

Frontiers in Public Health

Received: 22 October 2021 Accepted: 09 December 2021

Published: 18 January 2022

Citation:

Gao W, Li W, Zang Y, Zhong Y and Wu H (2022) Stratification of Health

Professional Education and lts Funding Disparities: Evidence From

China During the Period of

1998-2017.

Front. Public Health 9:800163. doi: 10.3389/fpubh.2021.800163
Background: The finance of health professional education (HPE) is of immense importance for effective and sustainable health systems, yet relevant empirical research was scarce due to the lack of financial data. The study aimed to bridge the gap by presenting the scenario of finance for health professional institutions (HPIs) of different tiers in China and exploring how the stratification of institutions affected their funding disparities.

Methods: The study employed data collected from the Ministry of Education in China, and selected the HPIs mainly based on the World Directory of Medical Schools. The funding levels and disparities of China's HPls during the period (1998-2017) were analyzed with descriptive statistics, and the indicators of funding per institution and funding per student were both considered. The average funding in HPIs was presented by tiers, and the Gini coefficient and Theil index were employed to describe the differences in financing among HPls over the span.

Results: The study found that the number of HPls has kept growing over the past two decades, with both the funding per institution and the funding per student increasing steadily. Specifically, the average funding per institution of the three tiers increased by 31.5 times, 13.4 times, and 10.5 times separately, with the first-tier universities having an absolute advantage compared to lower tiers. As for the financing disparities among HPIs, the Gini coefficient of the funding per institution maintained to be over 0.5 , with the third-tier institutions scoring the highest, while the Gini coefficient of the funding per student all ranged approximately from 0.2 to 0.3 . Through the decomposition of the inequalities measured by the Theil index, the share of the between-tier difference in per-institution funding grew from 29.7 in 1998 to $77.9 \%$ in 2017.

Conclusions: The funding disparities between tiers of HPIs in China gradually became more accentuated, with the top-tier institutions taking up the largest share. Although the stratified development in HPE has posed a challenge to the unified quality assurance of medical personnel training, it may also be regarded as an effective pathway for developing countries like China to achieve stable development in health professional education.

Keywords: financing, health professional education, stratification, health professional institutions, funding disparities 


\section{INTRODUCTION}

Funding serves as the basis for the development of health professional education (HPE), which ensures normal and effective teaching activities in health professional institutions (HPIs). In particular, public financing should be allocated properly so as to improve efficiency in the national contexts (1). The extant research on higher education finance focuses mainly on fiscal inequality (2), performance-based funding policies (3), the impacts of financial incentives measures on student educational outcomes (4), as well as the determinants of government funding (5), etc. However, related fields have not formed a very clear outline of funding input in HPE and the financial situation of HPIs worldwide. Some studies have examined the financial investment in American medical schools $(6,7)$, while some others discussed the financing in postgraduate HPE (8), as well as the funding in residents (9), yet there is relatively little empirical research on the finance of HPE compared with the ample exploration on the financing of tertiary education (10). One of the important reasons, as stated in the report published in The Lancet in 2010, is that there is a lack of financial data in HPE (1).

A joint report Health Professionals for a New Century published by the global commission on education of health professionals for the 21st century noted that the HPE reform in the coming 100 years will require a series of enabling actions, such as enhancement of investment level of HPE, which is a key measure to advance the quality and equity of HPE (1). In the report, a macro estimation approach was adopted by examining the funding of higher education as well as the proportion to HPE, and results showed that the estimated funding per medical student was $\$ 122000$ worldwide in the year 2008. The estimated value in Western Europe was similar to those in North America (\$497000 and \$400 000, respectively), but was much lower in China ( $\$ 14000,1 / 35$ of North America, and 1/28 of Western Europe) (1).

The funding income of HPIs is directly related to the operational status of the HPIs and will influence the quality of medical students' training. In view of these realities, the commission's initiative is that each country and agency should consider doubling its investments in HPE over the next 5 years as an indispensable contributor for effective and sustainable health systems (1).

\section{STRATIFICATION OF THE HEALTH PROFESSIONAL EDUCATION IN CHINA}

\section{Horizontal Differentiation of Chinese Health Professional Institutions}

The Ministry of Education (MOE) in China has categorized higher education institutions into comprehensive universities

Abbreviations: AAMC, the Association of American Medical Colleges; HPE, Health professional education; HPIs, health professional institutions; MOE, Ministry of Education; NHC, National Health Commission; TCM, traditional Chinese medicine; WDMS, World Directory of Medical Schools; WFME, World Federation for Medical Education. and 11 types of single-subject colleges, including medicine and pharmacy colleges, natural sciences and technology colleges (11). In the early 21 st century, some highly competitive colleges of medicine and pharmacy merged into comprehensive universities in China (12); thus, HPE has been offered not only by colleges of medicine and pharmacy, but also by comprehensive universities which include medicine-related departments. In 2017, China had 631 comprehensive universities and 199 colleges of medicine and pharmacy, including both the undergraduate and vocational colleges (13).

China has cultivated the largest quantity of medical students worldwide, though its number of HPIs is not the largest (1). In 2017, Chinese higher education institutions enrolled 7.6 million students in total, with 0.5 million students being admitted into HPIs, accounting for $6.6 \%$ of the total (13). In general, Chinese health professional institutions consist of 11 disciplines, namely clinical medicine, nursing, dental medicine, traditional Chinese medicine (TCM), public health and preventive medicine, the combination of modern medicine with TCM, pharmaceutical science, traditional Chinese pharmaceutical science, forensic medicine, allied health and basic medicine (11). Taking clinical medicine as an example, its enrollment took up a large proportion of the total to medicine, but the proportion has been declining year by year, from 63.2 in 1998 to $31.6 \%$ in 2012, and then remained at around $30 \%$ in recent years. In addition, undergraduate enrollment accounts for about $50 \%$ of the total clinical enrollment, while the ratio of master's and doctoral degrees has increased with time, indicating the growing demand for higher educational attainment (14).

\section{Vertical Hierarchy of Higher Education Institutions in China}

A series of schemes have been consecutively launched by the Chinese government including Project 211, Project 985, and the Double First-Class program over years in order to improve the education in elite universities and to facilitate the development of tertiary education (15). Specifically, Project 211 was initiated in 1995 with the purpose of setting a priority to improve the education of leading universities and to enhance their research standards, and the selected 115 prestigious universities have received $70 \%$ of the national research funding from 1995 to 2008 (16). In 1998, Project 985 was launched to build worldclass universities and 39 elite universities were chosen to be equivalent to the US Ivy League, which have received substantial public funding and policy support (17). In the year 2015, the Double First-Class program, known as the continuation of the two previous projects with a broader geographical spread, was inaugurated aiming to build an outstanding higher education system with first-class universities and first-class disciplines. Altogether 137 universities out of over 2000 universities have been selected, which formed the three selectivity tiers of institutions. The tier 1 comprises 42 universities (including all 39 of the Project 985 institutions, and three additional universities from the former Project 211), which were regarded to have the potential to reach world-class standards. The tier 2 consists of 95 universities (mainly the former Project 211 institutions) which 
were identified to have strengths in particular disciplines with a solid foundation for development. The tier 3 refers to other non-Project 211 universities $(18,19)$.

The distribution of HPIs follows the overall layout of higher education in China (20). In terms of financing allocation, the funding of health professional institutions mainly comes from their competent authorities. HPIs of the top tiers in China are directly affiliated to the MOE or other central ministries, thus their financial resources are mainly from the central government. The second-tier HPI are institutions of higher education with key medical disciplines, which are directly affiliated to the National Health Commission (NHC), and jointly established by the NHC or the National Administration of Traditional Chinese Medicine, the MOE, as well as the local governments. The third-tier HPIs are mainly affiliated to the local ministries, so the local governments provide them the main financial support. There exists a mutual influence between the development situation of HPIs and their financial resources to some extent. Sufficient funding plays a basic and supportive role in ensuring the development of HPIs, while well-developed HPIs, in return, may attract further funding sources.

The extant literature has examined the cost and financial demand of general higher education, but little research has focused specifically on HPE that may function very differently. Relevant studies were either case studies of certain institutions or general analyses based on personal experience, which can hardly provide an overall picture of the national funding situations and disparities among HPIs in China. Therefore, this paper aimed to bridge the gap by analyzing the changing trends of the funding among HPIs of different tiers from 1998 to 2017, and exploring how the stratification of institutions affects the funding disparities across tiers.

\section{METHODS}

\section{Data Sources}

This study employed data collected from the MOE in China, which encompasses the funding status, student number, and basic information of institutions of higher education nationwide. It should be noted that the statistical calibers of financial revenue and expenditure in China are quite different from the US. The primary sources of funds for public higher educational institutions in China are fiscal appropriation, tuition, fees and scientific research income, operating income, donations and grants, funding for institutional infrastructure, as well as other funding from miscellaneous sources. The financial expenditure includes salaries, wages and employee benefits, purchased goods and services, capital outlay, and other expenditures. Since hospitals are organized and operated as legal entities independent from HPIs, the expense in medical services was not included in the data. HPIs in our study mainly refer to colleges and universities that offer the clinical medicine programs, and usually these universities also have programs of other medical disciplines. HPIs in our study have been selected through three steps: (1) A total of 160 HPIs in the mainland of China have been screened based on the World Directory of Medical Schools (WDMS) provided by the World Federation for Medical Education
(WFME) (21). (2) Our research excluded 22 private HPIs that were listed in the WDMS, given that the statistical calibers of financial revenue and expenditure are quite different between the public and private HPIs, and China's higher educational system is dominated by public institutions. (3) We checked the relevant data year by year from 1998 to 2017 considering that the annual lists of HPIs varied since the clinical medicine programs had been established in different years. Thus, all the HPIs in our paper are public institutions offering degree programs, and in accordance with the Double First-Class initiative, this paper posits a classification of HPIs into three tiers. The tier 1 HPIs are key universities that have the potential to reach world-class standards; the tier 2 HPIs are institutions with key disciplines; and the tier 3 HPIs are other institutions. We used the 2017 US dollar constant price as the measurement standard by adjusting the funding data based on China's consumer price index (CPI) in 2017, and then converting Chinese Yuan to US Dollar ( 1 USD $\approx$ $6.752 \mathrm{CNY}$ ) according to the exchange rate in 2017 (22).

\section{Data Analysis: Gini Coefficient and Theil Index}

The study aimed to present the funding levels and disparities of different tiers of China's HPIs with descriptive statistics. We first compared the means of funding in HPIs when analyzing the finance distributions as well as changes across years, and the indicators of both funding per institution and funding per student were considered in our analysis. Furthermore, the Gini coefficient and Theil index were employed to describe the differences in finance among HPIs over the years. All the statistical analyses were performed using Stata version 15.1. The calculation of both Gini coefficient and Theil index of funding per institution and funding per student comes from the study by Cowell (23). The Gini coefficient, derived from the Lorenz curve framework, ranges between 0 and 1, indicating the income distribution from perfectly equitable to perfectly inequitable $(24,25)$. According to the United Nation standard, a Gini coefficient of $<0.2$ denotes absolute equality, while values of $0.2-0.3$ represent relative equality; values of $0.3-0.4$ stand for relatively reasonable inequality; values of $0.4-0.5$ mean relatively big inequality; values over 0.5 represent severe inequality. Gini coefficients can be calculated with the equation 1 . $n$ refers to the total number of samples in a certain year; $W_{i}$ stands for the percentage of funding of group 1 to $i$ in proportion to that of all HPIs.

$$
\text { Gini }=1-\frac{1}{n}\left(2 \sum_{i=1}^{n-1} W_{i}+1\right)
$$

Theil index, another measure of inequality, can decompose the differences from within-group and between-group separately, which ranges between 0 and infinity, with greater values indicating increasing levels of inequality (26-28). Theil Index can be measured through the equation $2 . n$ refers to the total number of the sample, which are divided into $k$ groups, and group $k$ was shown as $g_{k}$, while the number of the group $k$ was $n_{k} ; y_{i}$ and $y_{k}$ stand for the share of individual $i$ and the share of group $k$, respectively. Our study decomposed the Theil index by the three tiers of HPIs (see equation 3 and 4 ). $P_{b}$ refers to the 
TABLE 1 | Average funding per institution by tiers of health professional institutions: 1998-2017.

\begin{tabular}{|c|c|c|c|c|c|c|c|c|}
\hline \multirow[t]{2}{*}{ Year } & \multicolumn{2}{|r|}{ Total } & \multicolumn{2}{|r|}{ Tier 1} & \multicolumn{2}{|r|}{ Tier 2} & \multicolumn{2}{|r|}{ Tier 3} \\
\hline & $N$ & Mean (US\$ in millions) & $N$ & Mean (US\$ in millions) & $N$ & Mean (US\$ in millions) & $N$ & Mean (US\$ in millions) \\
\hline 1998 & 94 & 14.2 & 17 & 30.2 & 9 & 15.5 & 68 & 9.8 \\
\hline 1999 & 96 & 21.7 & 19 & 55.0 & 9 & 19.8 & 68 & 12.1 \\
\hline 2000 & 101 & 44.9 & 19 & 156.4 & 9 & 31.8 & 73 & 15.6 \\
\hline 2001 & 106 & 65.0 & 20 & 229.7 & 11 & 40.4 & 75 & 20.2 \\
\hline 2002 & 113 & 70.6 & 20 & 260.5 & 12 & 46.3 & 81 & 23.5 \\
\hline 2003 & 115 & 75.1 & 20 & 269.2 & 12 & 53.4 & 83 & 27.7 \\
\hline 2004 & 119 & 77.8 & 20 & 268.0 & 12 & 57.3 & 87 & 33.7 \\
\hline 2005 & 121 & 88.3 & 20 & 304.2 & 12 & 75.4 & 89 & 38.6 \\
\hline 2006 & 125 & 98.7 & 20 & 358.4 & 13 & 78.2 & 92 & 41.9 \\
\hline 2007 & 126 & 114.6 & 20 & 414.6 & 13 & 97.4 & 93 & 48.7 \\
\hline 2008 & 126 & 120.9 & 20 & 435.9 & 13 & 103.7 & 93 & 51.7 \\
\hline 2009 & 127 & 136.2 & 20 & 502.7 & 13 & 104.8 & 94 & 58.1 \\
\hline 2010 & 132 & 156.8 & 20 & 614.6 & 13 & 125.9 & 99 & 64.3 \\
\hline 2011 & 133 & 184.2 & 20 & 702.4 & 13 & 154.3 & 100 & 79.9 \\
\hline 2012 & 136 & 190.7 & 20 & 715.7 & 14 & 162.6 & 102 & 84.8 \\
\hline 2013 & 137 & 194.3 & 20 & 727.6 & 14 & 177.1 & 103 & 88.8 \\
\hline 2014 & 140 & 235.8 & 21 & 885.3 & 14 & 224.8 & 105 & 102.2 \\
\hline 2015 & 141 & 230.7 & 21 & 867.4 & 14 & 214.9 & 106 & 101.6 \\
\hline 2016 & 149 & 235.8 & 21 & 928.8 & 16 & 225.4 & 112 & 101.2 \\
\hline 2017 & 152 & 262.3 & 23 & 982.2 & 16 & 223.4 & 113 & 113.1 \\
\hline
\end{tabular}

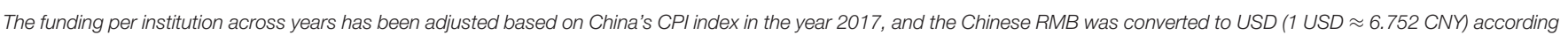
to the exchange rate in 2017.

share of between-tier difference. $P_{w}$ refers to the share of withintier difference. $T_{b}$ and $T_{w}$ represent the differences between and within tiers, used for calculating the share of intra-group and inter-group contribution to the total difference.

$$
\begin{aligned}
\text { Theil }= & \frac{1}{n} \sum_{i=1}^{n} \frac{y_{i}}{y} \ln \left(\frac{y_{i}}{y}\right)=\sum_{k=1}^{k} y_{k} \ln \frac{y_{k}}{\frac{n_{k}}{n}} \\
& +\sum_{k=1}^{k} y_{k}\left(\sum_{i \in g_{k}} \frac{y_{i}}{y_{k}} \ln \frac{\frac{y_{i}}{y_{k}}}{\frac{1}{n_{k}}}\right)=T_{b}+T_{w} \\
P_{b}= & \frac{T_{b}}{\text { Theil }} \times 100 \% \\
P_{w}= & \frac{T_{w}}{\text { Theil }} \times 100 \%
\end{aligned}
$$

\section{RESULTS}

\section{Distribution of Financial Resources in Health Professional Institutions}

Table 1 reports the number of HPIs and the average funding per institution by tiers between 1998 and 2017 in China. In general, the number of health professional institutions kept growing over the span. In the year 1998, there were altogether 94 HPIs, with 17 top-tier institutions, 9 s-tier institutions, and 68 third-tier institutions. By 2017, the number had increased to 152 HPIs in China, and the quantities for the three tiers were 23, 16, and 113, respectively. As for the per institution funding, it has risen by 17.5 times from $\$ 14.2$ million in 1998 to $\$ 262.3$ million in 2017 on average. Specifically, the average funding per institution of the three tiers increased by 31.5 times, 13.4 times, and 10.5 times separately. Until 2017, the average funding per institution for the three tiers has reached up to $\$ 982.2, \$ 223.4$, and \$ 113.1 million, respectively; and it is obvious that the first-tier institutions have received the largest share of financial resources.

Table 2 presents the average funding per student of HPIs in China during the period. The funding per student on average nationwide grew from $\$ 2,695$ in 1998 to $\$ 6,175$ in 2017, though there had been a slight decline in the early 21 st century possibly affected by the expansion of institutions. The average funding per student in all three tiers have experienced similar upward trends to $\$ 13,147, \$ 5,804$, and $\$ 4,728$ separately until 2017 , with the toptier universities had absolute advantage compared to the other two tiers. This suggested that training a student at top-tier health professional institutions in China usually costs up to $\sim \$ 65,700$ during the five years of undergraduate study. In addition, the average annual growth rate in the first-tier institutions reached $7.11 \%$, which was significantly higher than its counterparts in tier $2(4.5 \%)$ and tier $3(3.4 \%)$ institutions.

\section{Funding Disparities Across Health Professional Institutions in China}

Figure 1 presents the Gini coefficients of the funding per institution and the funding per student in HPIs over years. Overall, both the Gini coefficient of the funding per institution and the funding per student had increased steadily from 1998 to 2000 , after which they experienced a slow decline before they 
TABLE 2 | Average funding per student by tiers of health professional institutions: 1998-2017.

\begin{tabular}{|c|c|c|c|c|}
\hline Year & Total (US\$ in thousands) & Tier 1 (US\$ in thousands) & Tier 2 (US\$ in thousands) & Tier 3 (US\$ in thousands) \\
\hline 1998 & 2.695 & 3.560 & 2.513 & 2.492 \\
\hline 1999 & 3.083 & 4.491 & 2.627 & 2.727 \\
\hline 2001 & 3.248 & 5.900 & 2.704 & 2.547 \\
\hline 2002 & 3.125 & 6.035 & 2.548 & 2.434 \\
\hline 2005 & 3.283 & 5.323 & 3.754 & 2.736 \\
\hline 2006 & 3.372 & 6.104 & 3.451 & 2.732 \\
\hline 2007 & 3.658 & 6.689 & 3.184 & 3.034 \\
\hline 2008 & 3.743 & 6.893 & 3.218 & 3.099 \\
\hline 2009 & 3.899 & 7.711 & 3.260 & 3.129 \\
\hline 2013 & 4.984 & 9.803 & 5.244 & 3.977 \\
\hline 2014 & 5.734 & 11.825 & 6.304 & 4.395 \\
\hline 2015 & 5.538 & 11.499 & 5.666 & 4.295 \\
\hline 2016 & 5.619 & 12.275 & 5.871 & 4.277 \\
\hline 2017 & 6.175 & 13.147 & 5.804 & 4.728 \\
\hline
\end{tabular}

The funding per institution across years has been adjusted based on China's CPI index in the year 2017, and the Chinese RMB was converted to USD (1 USD $\approx 6.752$ CNY) according to the exchange rate in 2017.

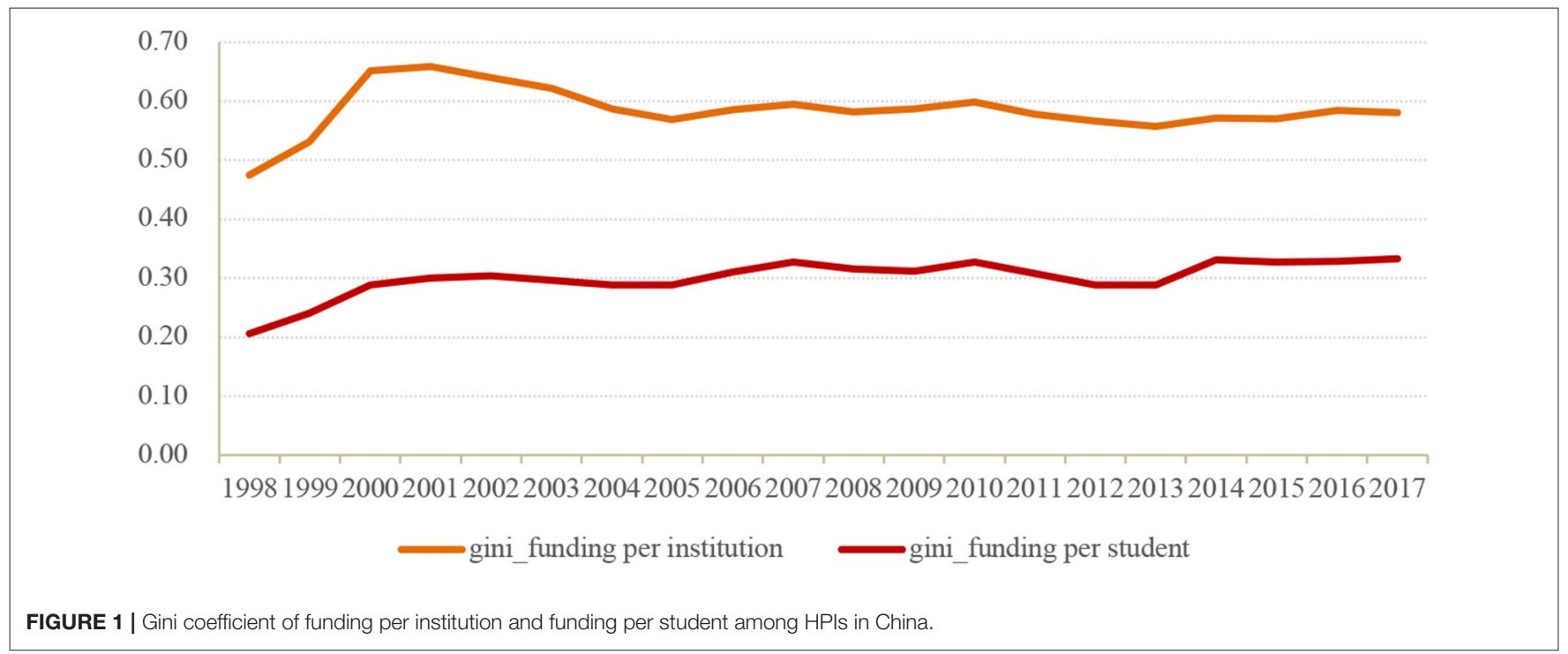

started to remain stable since 2005. The Gini coefficient of the funding per institution maintained to be over 0.5 , while the Gini coefficient of the funding per student ranged approximately from 0.2 to 0.3 , indicating that the distribution of financial resources among institutions were quite inequal, while the funding was relatively equally allocated among students in general.

Figures 2, 3 show the disparities in per institution funding in HPIs across tiers. According to Figure 2, the Gini coefficients in HPIs of the three tiers all experienced an overall decline regarding the funding per institution over years. In general, the financial resources were more equitably distributed within the top tiers of institutions, while the funding allocation among the lower-tier colleges and universities appeared to be more unfair. Figure 3 further distinguishes the differences between the three tiers of the HPIs in question and the differences within each tier of institutions. The share of within-tier difference declined from $70.3 \%$ in 1998 to $22.1 \%$ in 2017, indicating that the differences in per institution funding were more distinct within each tier 


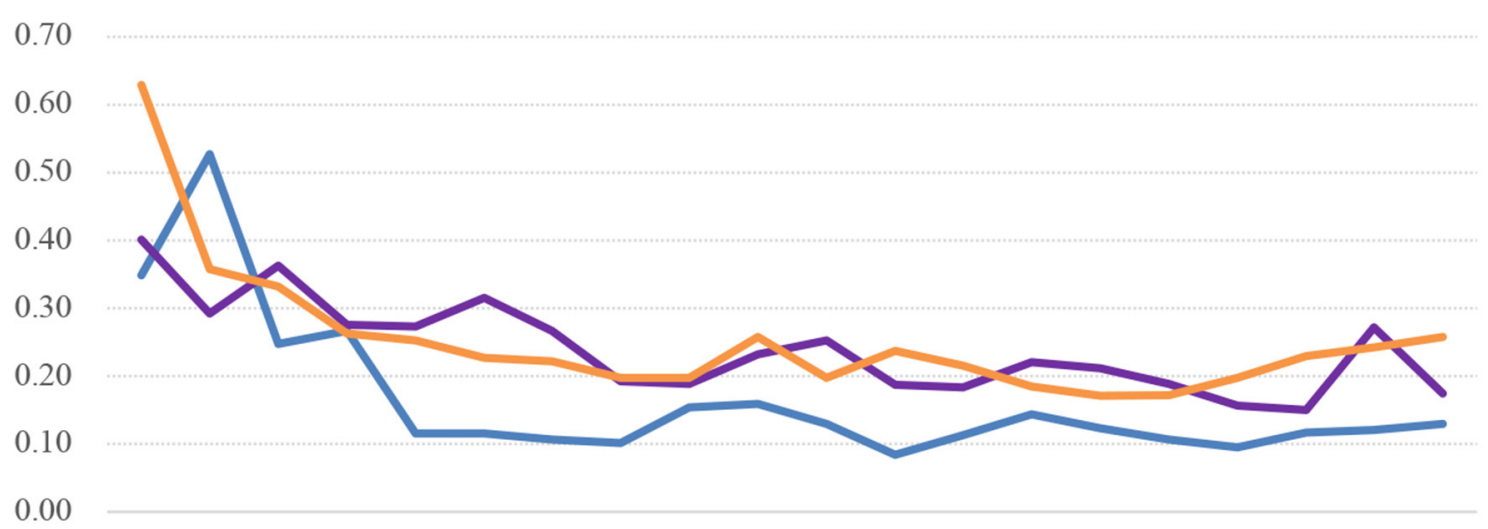

19981999200020012002200320042005200620072008200920102011201220132014201520162017

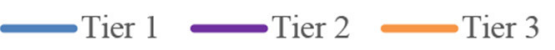

FIGURE 2 | Gini coefficient of funding per institution in HPIs of three tiers in China.

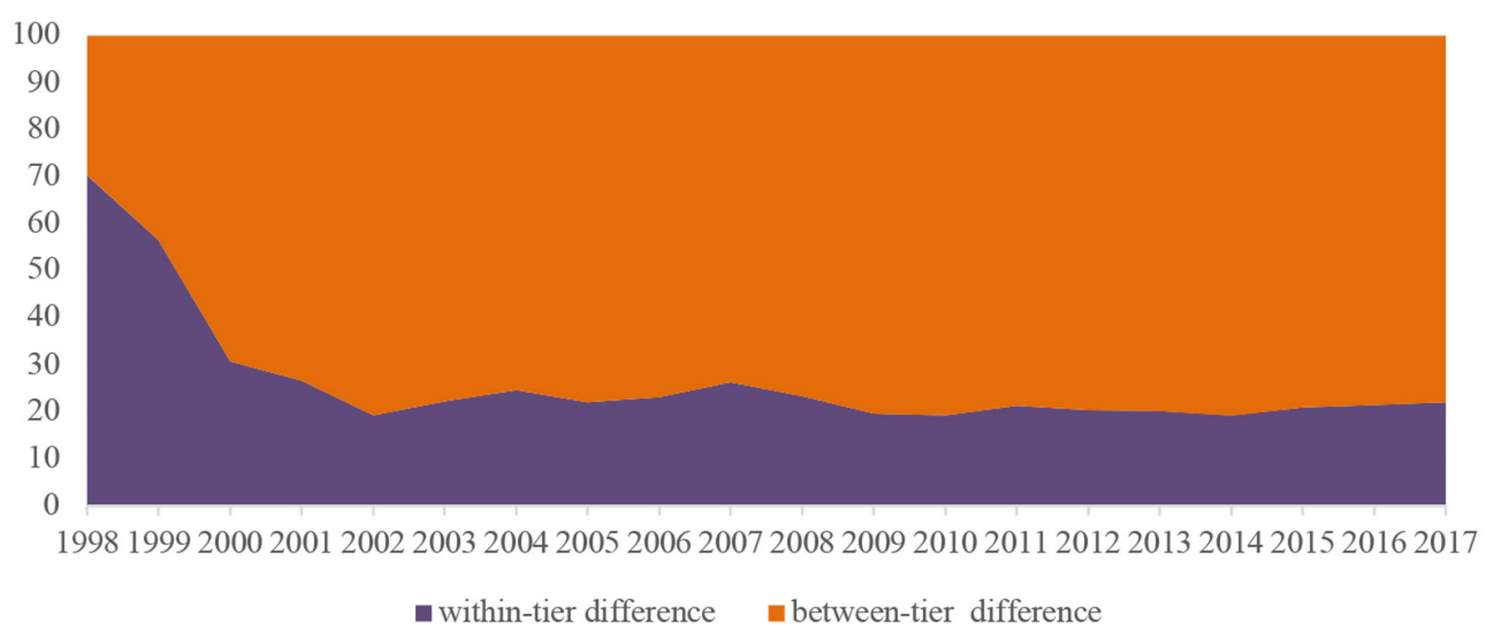

FIGURE 3 | Within-tier and between-tier differences in funding per institution among HPIs in China.

from 1998 to 1999, and since the expansion of higher education, the funding disparities were increasingly noticeable between different tiers after 2000.

Figures 4, 5 display the per student funding differences in HPIs across tiers. As shown in Figure 4, the Gini coefficient of funding per student across all levels of institutions has fluctuated over years ranging from 0 to 0.25 , presenting a relatively fair layout in each tier of health professional institutions.

As for the shares of differences within groups and between groups, the difference of per student funding within groups witnessed a general decrease from $83.5 \%$ in 1998 to $49.7 \%$ in 2017, suggesting the stratification of HPIs has played an increasingly important role in explaining the disparities in the funding per student. Nevertheless, the difference within groups still accounts for a relatively large proportion, which can be attributed to the differences in the scale of institutions within the same tier (Figure 5).

\section{DISCUSSION}

\section{A Move on the Financing Gaps in Health Professions Education in China}

The descriptive statistics in our study showed that the number of HPIs and the average funding per institution of all tiers grew steadily between 1998 and 2017. This was directly related to China's college expansion since 1998. In order to promote economic growth, and achieve national quality improvement, the MOE in China implemented the Educational Promotion Action Plan for the 21st Century which rapidly expanded the enrollment in tertiary education (29). Meanwhile, the Chinese government has significantly increased the expenditure on higher education (20). As stated in a series of related regulations such as the Education Law (30), the growth of government funding support for education at all levels should overtake the regular budget of the same level, and the funding per student, as well as 


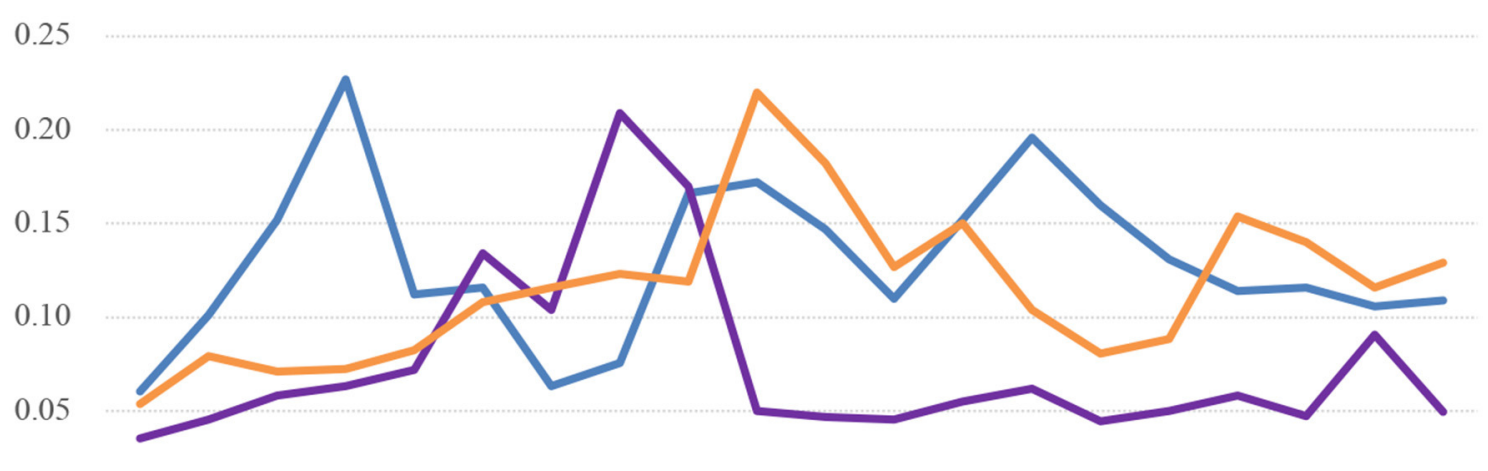

0.00

19981999200020012002200320042005200620072008200920102011201220132014201520162017

$\longrightarrow$ Tier $1 \longrightarrow$ Tier $2 \longrightarrow$ Tier 3

FIGURE 4 | Gini coefficient of funding per student in HPIs of three tiers in China.

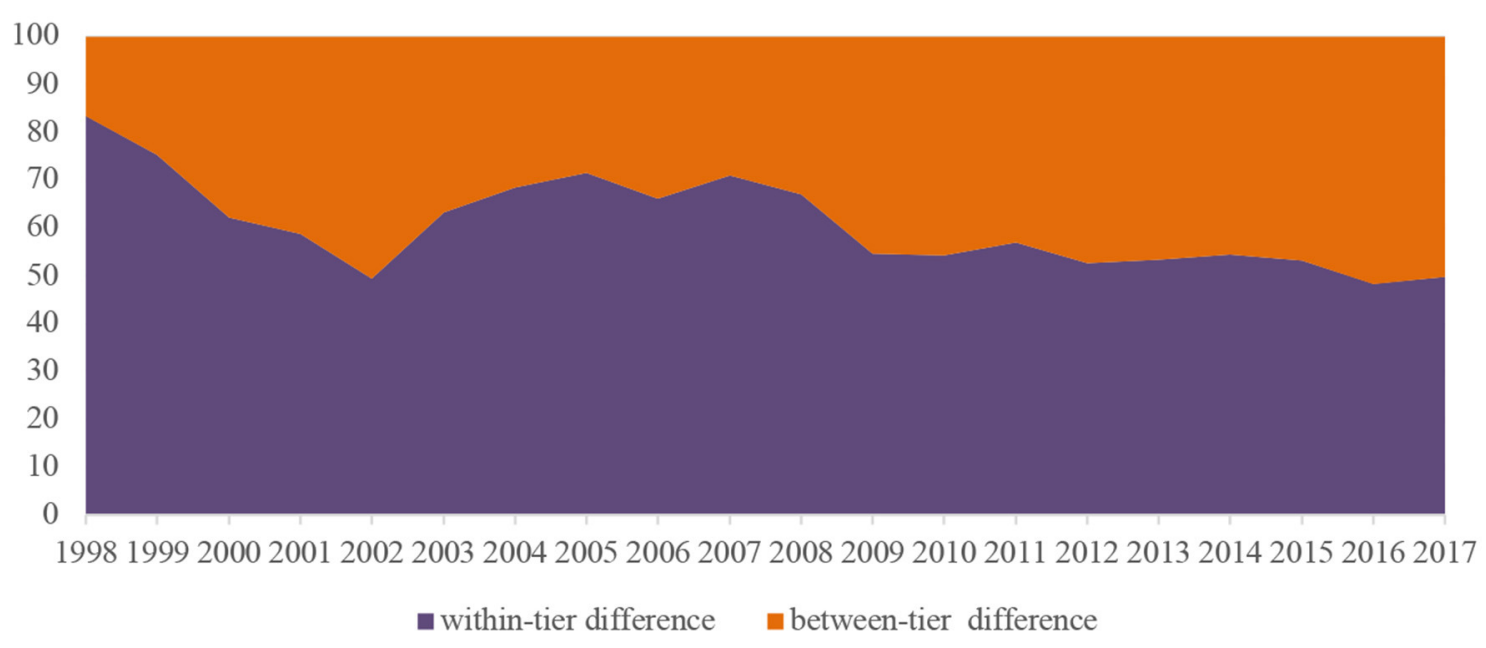

FIGURE 5 | Within-tier and between-tier differences in funding per student among HPIs in China.

the salaries for faculty, should increase gradually. Nevertheless, the rapid expansion in tertiary education in the first few years aggravated the financial burden of governments at all levels, which, regrettably but inevitably, led to the stagnation in the increase of funding per student (31). Although the funding per institution nationwide increased by 17.5 times from 1998 to 2017, the funding per student had only a limited increase of 1.3 times during the period. The basic structure of national higher education was not finalized until around 2008 (30), after which the enrollment numbers have gradually stabilized and the increase in per-student appropriation has gained momentum.

The Chinese government has always attached great importance to the development of the healthcare system and HPE, and have provided with policy guarantee for the year-on-year growth in medical finance. Particularly in the past decade, the Chinese government has established a mechanism of attracting funding through multiple channels in order to support HPE. By 2012, the central government had raised funding per health professional student to $\$ 4,000$ ( $¥ 27,000$ Chinese Yuan), reaching the highest standard of students' educational cost in various disciplines $(32,33)$. In 2014, the MOE pointed out that it was necessary to improve the multi-channel financing mechanism, coordinate the use of resources from all parties including the government, universities, hospitals, and society, and further increase funding in HPE (34). China has gradually formed a diversified pattern of finance on the basis of governmental appropriation and multi-channel funding. Indeed, the growth rate of per-student funding of HPIs in China has overtaken the average level of OECD countries (35).

Despite of the narrowing gaps in the finance of HPE with the developed countries and regions, China still needs to take more measures to further raise funding in HPE and attract more social capital to higher educational institutions. For instance, the average revenue per institution among the 84 fully-accredited 
public medical schools of the Association of American Medical Colleges (AAMC) in 2017 amounted to \$717 million (36), which was almost 3 times more than the 152 public HPIs offering diploma degree in China (\$262 million). Taken the small enrollment scale of American medical schools into consideration, the gaps in funding per student may be even greater. It is gratifying that the Chinese government has made continuous and unremitting efforts in the investment of education by regarding the development of education as infrastructure construction, and the funding in education as a basic investment (29). In 2008-2009, the Chinese government shifted its focus from HPIs affiliated with the central government to local health professional institutions (37), which required further increases in both perstudent funding and special funds in teaching (31). It has been advocated that the financial needs of HPE should be satisfied through three main sources, i.e., the investment of governments at all levels, the share in educational costs by individuals and social capital, and the support for school-run industries in selffinancing. China will gradually establish a financial system for HPE that suits its national conditions as well as the status of health professional institutions.

\section{Distinct Hierarchy in Health Professional Institutions in China}

The results above indicated that the financial differentiation between tiers of HPIs gradually became more accentuated, while the funding gaps contracted within tiers. Concerning the structure of funding sources, the finance system of tertiary education relies mainly on governmental funding, supplemented by multiple channels including tuition, school-run industries, and social donations (20). As for the financing from the competent authorities, the funding of the first-tier universities usually comes from the central government, which is financially more abundant than local governments, especially after the implementation of the tax system reform in 2001. The secondtier universities have two main sources, i.e., the local government finance as well as the special funding from relevant ministries and commissions; and the colleges and universities at the third tier rely heavily on local governments. Considering that the economic development is unbalanced among different provinces and cities, and that local governments may shoulder the financing of multiple institutions, the non-Project 211 HPIs receive only limited funding support, and their fiscal revenues are quite heterogeneous compared with the upper tiers $(38,39)$. Apart from governmental finances, tuition fees also play significant roles in the financing of higher educational institutions, and since the public institutions are uniformly priced in China, revenues from tuition fees may be different regarding the scales of institutions. In 2017, governmental funding accounted for 58.2\% of the total financing, while tuition fees comprised $22.5 \%$, with the remaining $19.3 \%$ from other sources. It should be noted that the financing excluding governmental funding and tuition for the three tiers of institutions accounted for 47.4, 21.6, and $12.9 \%$, respectively, suggesting that it is more difficult for the lower-tier colleges and universities to obtain funds from other channels under the stratified structure. In addition, with regard to the geographic disparity of health education financing, the funds of medical schools in eastern China were significantly higher than the central part, leading to a distinct regional disparity nationwide (35).

The stratification of tertiary education universities in China has increased substantially after the initiation of Project 211 and Project 985 at the end of the 20th century. Those selected key universities, with outstanding academic accumulation and profound historical heritage and often located in the political or economic centers of administrative regions, have been obtaining both resource support and policy preferences. In return, the academic strengths and reputation of the upper-tier universities gradually became dominant, which necessarily attracted more non-governmental funding and social donations. Thus, the Matthew effect caused by the stratification of institutions has progressively widened the gap in funding between different tiers of institutions. The Double First-Class program with a broader geographical spread in 2015 marked a transition in the competition between institutions from an inherent identity mechanism to a more open competition mechanism. The Double First-Class program adopts a rolling elimination system with innovative indicators for evaluation and encourages more institutions to participate in competition and construction. All the colleges and universities should be evaluated every five years, and those which cannot reach the standards of first-class universities and first-class disciplines would be forced out. This, undoubtedly, will reduce the stratification of health professional institutions and strengthen their internal constructions.

\section{Challenges and Opportunities of Stratified Health Professional Education Worldwide}

The analysis in this paper provides an overall picture of finance for HPIs in China, which is of great importance for understanding the challenges and opportunities confronted by HPE worldwide. In fact, the decomposition of funding in the US higher education institutions from 2004 to 2017 also revealed increasing inequality in total expenditures and decreasing inequality in per-student funding (2).The stratified development in HPE has posed a severe challenge to the unified quality assurance for medical personnel training. Health professional institutions of lower tiers are disadvantageous in competitions concerning their scarcity of high-level talents, the lagging of comprehensive education reforms, and the limited capability to attract external resources. This will restrict their further development and progress, and the quality of their student training may also hardly be guaranteed.

Nevertheless, the stratification of HPIs in China can be regarded as intentional action to a certain extent. For developing countries as large as China, it is unrealistic to expect health professional institutions to cultivate students with uniform standards. The academic capabilities are inherently heterogeneous for HPIs of different tiers in different regions, which, definitely, would exert differential impacts on the quality of student output. Therefore, it is of practical significance to first give priority to the development of high-level institutions with limited resources, establish their exemplary role and then 
facilitate the development of other levels of institutions. The progress of Chinese HPE has been widely acknowledged in the recent decades. According to Academic Ranking of World Universities published by Shanghai Jiao Tong University, 17 institutions in China were shortlisted in the top 500 in 2017, while only 6 were shortlisted in 2005 (40). The guarantee of the quality of personnel training in HPIs can directly promote the improvement of the quality of medical and health services. According to the Lancet ranking of 195 countries and regions in terms of medical quality and accessibility, China achieved a substantial leap with the ranking from the 110th in 1995 to the 48th in 2016. Moreover, China performs significantly better than the average level of middle-income and high-income countries in respect of the main health indicators of residents assured by medical and health services.

The hierarchical development of HPE can be regarded as an effective pathway for developing countries. It may allow certain key universities to take the lead in exploring effective ways of education reform and in establishing pilots for new policies and methodologies. In addition, students from those key universities can be regarded as outstanding talents to meet complicate needs of society. More importantly, the establishment of an open competition mechanism such as the Double FirstClass program in China can reduce the solidification of the superior status for certain institutions and promote healthy competition by evaluating institutions regularly. In this way, stable development of HPE can be advocated by maintaining the competitive and cooperative relationship between different tiers of colleges and universities.

There were several limitations of this study. First, the paper explored the financing distribution among HPIs, which included not only independent colleges of medicine and pharmacy, but also comprehensive universities with medicalrelated departments; thus, the funding per institution might be overestimated. Meanwhile, given that students majoring in health professions usually have access to larger shares of financing resources compared to students of other disciplines (32), the perstudent funding in our study may be underestimated. In addition, the HPE in our study mainly refers to undergraduate study, failing to take postgraduate study and continuing education into consideration.

\section{CONCLUSION}

This paper presents an overview of the education finance of HPIs in China over the span (1998-2017), and explores changes in the disparities among different tiers of institutions.

\section{REFERENCES}

1. Frenk J, Chen L, Bhutta ZA, Cohen J, Crisp N, Evans T, et al. Health professionals for a new century: transforming education to strengthen health systems in an interdependent world. Lancet. (2010) 376:192358. doi: 10.1016/S0140-6736(10)61854-5

2. Cheslock JJ, Shamekhi Y. Decomposing financial inequality across US higher education institutions. Eco Educ Rev. (2020) 78:102035. doi: 10.1016/j.econedurev.2020.102035
The main conclusions are as follows: First, the number of HPIs in China has kept growing over the past two decades, with both the funding per institution and the funding per student increasing steadily. Second, the funding per institution as well as the funding per student in the top-tier institutions maintained to be much higher than those in the lower-tier institutions, while the gap has continued to be widened in recent years. Third, the school funding was more equitably distributed within each tier of institutions, with the Gini coefficient of each tier remaining under 0.3 over the past two decades; yet the share of between-tier difference rising from $29.7 \%$ to $77.9 \%$, indicating that the disparity between different tiers become more dominant over years. In particular, the financial resources were more equitably distributed within the top tiers of institutions, while the funding allocation among the lowertier colleges and universities appeared to be more unfair. In sum, the paper has proposed the need for increasing the perstudent funding in China, and emphasized the probability of the stratified development of HPIs for developing countries and regions.

\section{DATA AVAILABILITY STATEMENT}

The raw data supporting the conclusions of this article will be made available by the authors, without undue reservation.

\section{AUTHOR CONTRIBUTIONS}

HW, WG, and WL conceived the work. WG, WL, and YZ performed data analysis. WG, WL, and YZ were involved in manuscript writing. $\mathrm{HW}, \mathrm{YZ}$, and $\mathrm{YZh}$ were involved in manuscript revision. WG and WL contributed equally to this work. All authors contributed to the article and approved the submitted version.

\section{FUNDING}

This research was funded by the National Natural Science Foundation of China for Young Scholars, P.R.C., grant number 71804005 .

\section{ACKNOWLEDGMENTS}

Grateful acknowledgment is made to the support of National Center for Health Professions Education Development and Peking University, China. 
and their contributions. Stud Higher Educ. (2020) 2:1-14. doi: $10.1080 / 03075079.2020 .1750586$

6. Jones RF, Ganem JL, Williams DJ, Krakower JY. Review of US medical school finances, 1996-1997. JAMA. (1998) 280:813-18. doi: 10.1001/jama.280.9.813

7. Krakower JY, Coble TY, Williams DJ, Jones RF. Review of US medical school finances, 1998-1999. JAMA. (2000) 284:112729. doi: 10.1001/jama.284.9.1127

8. Rich EC, Liebow M, Srinivasan M, Parish D, Wolliscroft JO, Fein O, et al. Medicare financing of graduate medical education. J Gen Int Med. (2002) 17:283-92. doi: 10.1046/j.1525-1497.2002.10804.x

9. Ahmad FA, White AJ, Hiller KM, Amini R, Jeffe DB. An assessment of residents' and fellows' personal finance literacy: an unmet medical education need. Int J Med Educ. (2017) 8:192. doi: 10.5116/ijme.5918.ad11

10. Foo J, Cook DA, Walsh K, Golub R, Maloney S. Cost evaluations in health professions education: a systematic review of methods and reporting quality. Med Educ. (2019) 53:1196-208. doi: 10.1111/medu.13936

11. Ministry of Education of the People's Republic of China. Undergraduate Professional Catalog of General Institutions (2020). Available online at: http:// zwfw.moe.gov.cn/dynamicDetail?id=08a45c1fd1994cela939f071fda0da16\& title $=1$ (accessed August 13, 2021).

12. Hou J, Michaud C, Li Z, Dong Z, Sun B, Zhang J, et al. Transformation of the education of health professionals in China: progress and challenges. Lancet. (2014) 384:819-27. doi: 10.1016/S0140-6736(14)61307-6

13. Liu C, Li J. China Statistical Yearbook. Beijing: China Statistics Press (2017) 4p.

14. Hou J, Luo Y, Wang Z, Meng Q. Study on the scale and structure of health professional education in China's colleges and universities from 1998 to 2012. Chin J Med Educ Res. (2016) 15:114-19.

15. Yeung WJ. Higher education expansion and social stratification in China. Chin Soc Rev. (2013) 45:54-80. doi: 10.2753/CSA2162-0555450403

16. Shu $F$, Sugimoto $C R$, Larivière $V$. The institutionalized stratification of the Chinese higher education system. Quant Sci Stud. (2021) 2:32734. doi: 10.1162 /qss_a_00104

17. Hu J, Liu H, Chen Y, Qin J. Strategic planning and the stratification of Chinese higher education institutions. Int J Educ Dev. (2018) 63:3643. doi: 10.1016/j.ijedudev.2017.03.003

18. Ministry of Education of the People's Republic of China. List of Institutions of "Double First-Class" Initiative (2017). Available online at: http://www.moe.gov.cn/s78/A22/A22_ztzl/ztzl_tisylpt/sylpt_jsgx/201712/ t20171206_320667.html (accessed August 14, 2021).

19. Ministry of Education, List of National Institutions of Tertiary Education (2017). Available online at: http://www.moe.gov.cn/srcsite/ A03/moe_634/201706/t20170614_306900.html (accessed August 14, 2021).

20. Wu H, Li W, Xie AN, Kang L, Yang K, Wang, et al. Funding of health professional education: China's 20-year process and a global comparison. Med Educ. (2021) 00:1-9. doi: 10.1111/medu.14577

21. World Federation for Medical Education (WFME). World Directory of Medical Schools (2018). Available online at: https://search.wdoms.org (accessed August 13, 2021)

22. National Bureau of Statistics of the People's Republic of China. National Data (2017). Available online at: http://data.stats.gov.cn/easyquery.htm?cn= $\mathrm{C} 01 \& z b=A 060 J \& s j=2018$ (accessed August 13, 2021).

23. Cowell FA. Estimation of inequality indices. Dordrecht: Springer (1999). p. 269-89.

24. De Maio FG. Income inequality measures. J Epidemiol Commun Health. (2007) 61:849-52. doi: 10.1136/jech.2006.052969

25. Dietze PM, Jolley DJ, Chikritzhs TN, Clemens S, Catalano P, Stockwell T. Income inequality, and alcohol attributable harm in Australia. BMC Public Health. (2009) 9:1-9. doi: 10.1186/1471-2458-9-70

26. Conceição P, Ferreira P. The Young Person's Guide to the Theil Index: Suggesting Intuitive Interpretations and Exploring Analytical Applications. Austin, UTIP Working Paper No. 14 (2000).

27. Bosmans K, Cowell FA. The class of absolute decomposable inequality measures. Eco Lett. (2010) 109:154-6. doi: 10.1016/j.econlet.2010.09.007

28. Lukwa AT, Siya A, Zablon KN, Azam JM, Alaba OA. Socioeconomic inequalities in food insecurity and malnutrition among under-five children: within and between-group inequalities in Zimbabwe. BMC Public Health. (2020) 20:1-11. doi: 10.1186/s12889-020-09295-Z
29. Ministry of Education of the People's Republic of China. Educational Promotion Action Plan for the 21st Century (1998). Available online at: http://www.moe.gov.cn/jyb_sjzl/moe_177/tnull_2487.html. (accessed August 20, 2021).

30. Ministry of Education of the People's Republic of China. Education Law of the People's Republic of China (2015). Available online at: http://www.moe.gov.cn/ s78/A02/zfs_left/s5911/moe_619/201601/t20160125_228816.html (accessed August 20, 2021).

31. Ministry of Education of the People's Republic of China, Ministry of Health of the People's Republic of China. Several Opinions on Strengthening the Work of Health Professional Education and Improving the Quality of Health Professional Education (2019). Available online at: http://www.gov.cn/ gongbao/content/2009/content_1371356.htm. (accessed August 21, 2021).

32. Ministry of Education of the People's Republic of China. National Medical Education Reform has Made Significant (2017). Available online at: http:// www.moe.gov.cn/jyb_xwfb/s5147/201707/t20170711_309097.html (accessed August 14, 2021).

33. Preliminary Establishment of a Standardized Medical Education System With Chinese Characteristics-A Major Breakthrough in Medical Education Reform. Beijing: China Education News (2017).

34. Six departments including the Ministry of Education of the People's Republic of China. Opinions of Six Departments Including the Ministry of Education of the People's Republic of China on Deepening the Reform of Clinical Medical Talent Training Through Collaboration Between Medical and Education. Available online at: http://www.moe.gov.cn/srcsite/A22/s7065/ 201407/t20140714_178832.html (accessed August 21, 2021).

35. Li W, Wu H, Zang Y. Changes in funding for medical schools in China: a comparison based on the eastern, central and western regions of China. Chin J Health Policy. (2020) 13:7. doi: 10.3760/cma.j.cn115259-20191023-00879

36. Association of American Medical Colleges (AAMC). Revenue Supporting Programs Activities at Fully Accredited U.S. Medical Schools (Public vs. Private). Available online at: https://www.aamc.org/data-reports/ faculty-institutions/report/us-medical-school-revenues (accessed August $22,2021)$.

37. Ministry of Education of the People's Republic of China, Ministry of Health of the People's Republic of China. Several Opinions on Implementing the Comprehensive Reform of Clinical Medical Education (2019). Available online at: http://www.moe.gov.cn/srcsite/A08/moe_740/s7952/201205/t20120507_ 166951.html (accessed August 13, 2021).

38. Huaijin Q, Qingyue M, Yude C. Analyzing the present situation of financing and expenditure in china higher medical colleges and universities. Chin Health Eco. (2003) 01:39-42.

39. Huaijin Q, Qingyue M, Yude C. Measuring the cost of education in china higher medical colleges and universities. Chin Health Eco. (2003) 03:25-29.

40. Academic Ranking of World Universities (ARWU). 2017 Global Ranking of Academic Subjects: Clinical Medicine. Available online at: http:// www.shanghairanking.com/rankings/gras/2017/RS0401 (accessed August 13, 2021).

Conflict of Interest: The authors declare that the research was conducted in the absence of any commercial or financial relationships that could be construed as a potential conflict of interest.

Publisher's Note: All claims expressed in this article are solely those of the authors and do not necessarily represent those of their affiliated organizations, or those of the publisher, the editors and the reviewers. Any product that may be evaluated in this article, or claim that may be made by its manufacturer, is not guaranteed or endorsed by the publisher.

Copyright (๑) 2022 Gao, Li, Zang, Zhong and Wu. This is an open-access article distributed under the terms of the Creative Commons Attribution License (CC BY). The use, distribution or reproduction in other forums is permitted, provided the original author(s) and the copyright owner(s) are credited and that the original publication in this journal is cited, in accordance with accepted academic practice. No use, distribution or reproduction is permitted which does not comply with these terms. 